\author{
Military Technical College \\ Kobry El-Kobbah, \\ Cairo, Egypt
}

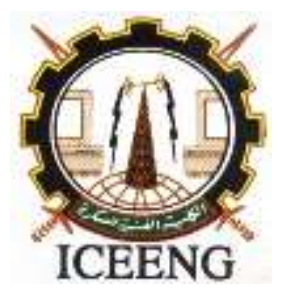

\author{
$11^{\text {th }}$ International Conference \\ on Electrical Engineering \\ ICEENG 2018
}

\title{
Modern Innovative Electricity Transmission Technologies
}

\author{
Eslam I Al-Saba*
}

\begin{abstract}
Nowadays technology plays a main role in our life. This era is innovative technology time. Many obstacles appear in power transmission. In the past, the electrical power used to be transmitted by wiring. This way was effective because of short transmission distance. But now with the spreading, long distance transmission and varying requirements use electricity, about half of the electricity resources are wasted during its transmission and distribution. Thus, the world needs an innovative solution for electrical transmission power especially the high power.

Wireless technology invades all life fields due to its merits. One of these merits is the cost associated with maintaining direct connectors. Beside to usefully daily charging electronic instruments. Other helpful merit is the wireless transmitting power of objects that should be hermetically sealed or sterilized. Also, electronic devices can be fully enclosed to reduce or overcome the risk of corrosion. Due to these merits and others, the wireless power transmission should be used as a solution for power transmission. So, wireless electricity (WiTricity) technology is used. This paper presents the WiTricity technology.
\end{abstract}

\section{KEY WORDS}

WiTricity, Induction, Resonant, Microwave, Magnetron, Traveling Wave Tube Amplifier, Klystron, Wireless transmission efficiency, Wireless power frequency bands.

\section{Introduction}

Wireless Power transfer is a previous idea elucidated by Nikola Tesla in the 1890s [1]. He used electromagnetic induction charge system. Thus, WiTricity can be called inductive power transfer. Resonant wireless power, inductive coupling beside resonant power transfer describes the fundamental process of wireless electricity transmission from the power source to the electrical load without connectors via air gap. The basis of a wireless power system basically comprises two coils, one of them is a transmitter and other is a receiver coil.

* Dept. of Electrical Engineering, Egyptian Academy For Engineering and Advanced Technology Affiliated To The Ministry of Military Production, Cairo, Egypt. 
Wireless power transfer techniques could be classified into radiative and nonradiative shown in figure 1 . The non-radiative techniques or near field power is transferred by electric fields using capacitive coupling between metal electrodes, or by magnetic fields using inductive coupling between coils of wire. Wireless technology is usually used by inductive coupling. The radiative techniques or far field power is transferred by beams of electromagnetic radiation. Therefore, these techniques can transfer power for long distances aiming the receiver.

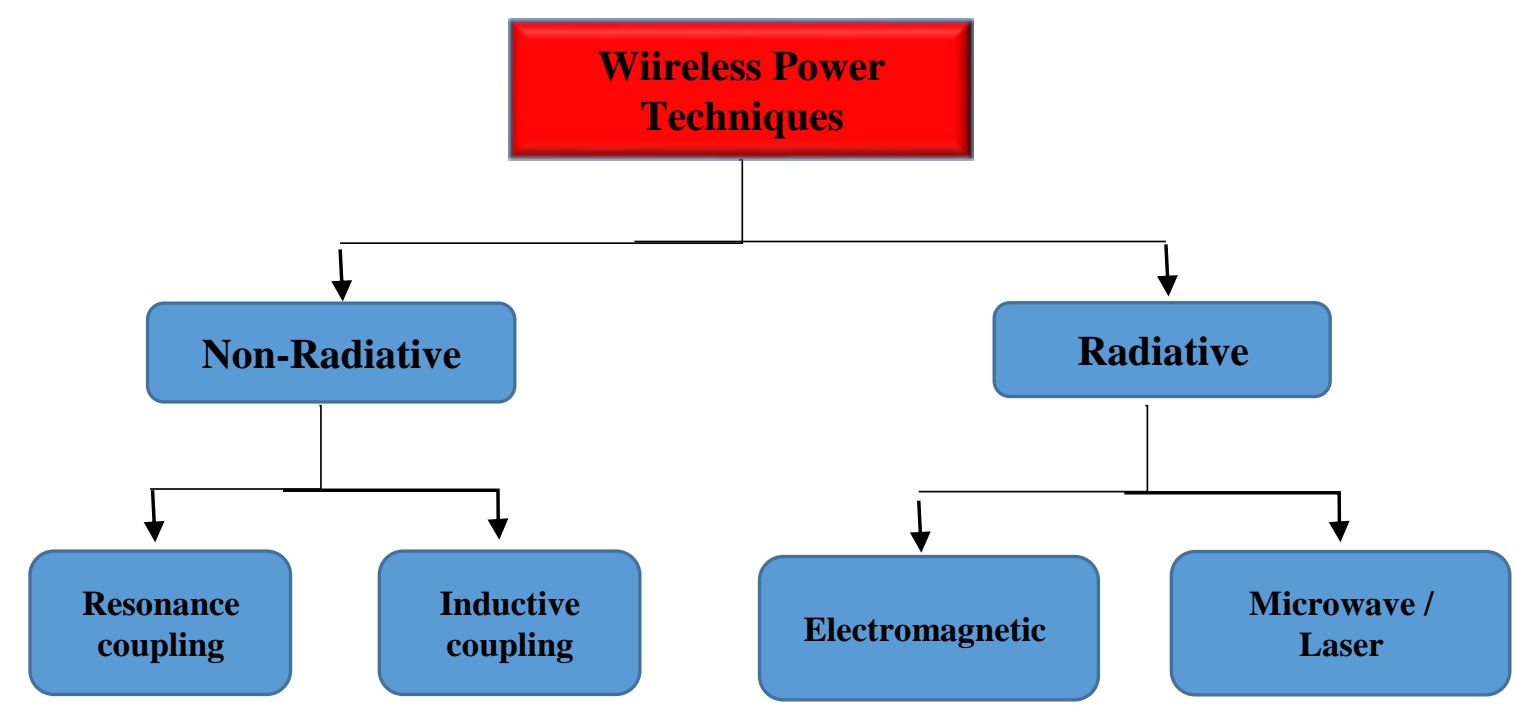

Fig. 1. Wireless power techniques

\section{Basic Principle of Wireless Electricity (witricity)}

The basic principle of Witricity concept depends on two circuits having same resonating frequency. Several methods and techniques are used for WiTricity. In the next section the paper shows commonly methods used in WiTricity.

\subsection{Magnetic Induction Method}

This method is a non-radiative type. It works by using mutual induction. This technique occurs when two coils are inductively coupled with electrically isolated and the current in one of these coils changed uniformly as shown in figure 2. After that, an electromotive force gets induced in the other coil [2]. The mutual induction can be expressed by:

$M=\frac{\mu_{0} \mu_{r} N_{1} N_{2} A}{l}$

Where $\mu_{0}$ is free space permeability and it is equal to $4 \pi \times 10^{-7} \mathrm{H} / \mathrm{m}, \mu_{r}$ is relative permeability, $\mathrm{N}$ is a turn number of coil, $\mathrm{A}$ describes the area of cross section, and $I$ is the coils length.

In this method, the power is transmitted without using the traditional wires. Nevertheless, there are some restrictions like shorter range (a few $\mathrm{mm}$ if any), lower 
overall efficiency and tight coupling. Therefore, this method is unsuitable for wireless power transmission [3]. But, the efficiency and the operating range of this method can be improved to a considerable level by enhancing the resonance $[4,5]$. Figure 3 demonstrates the block diagram for wireless power transmission using magnetic induction method. The block diagram start with feeding source in transmission using a DC power supply. The voltage source is in range of Voltas; it operate in short range and low power transmission. Then, the next step is oscillation using LC circuit to generate the output power for the sender coil which create the magnetic field and the high frequency AC signal. In the receiver side, receiver coil inducts power and converts it to DC signal by rectifier circuit to load power in battery.

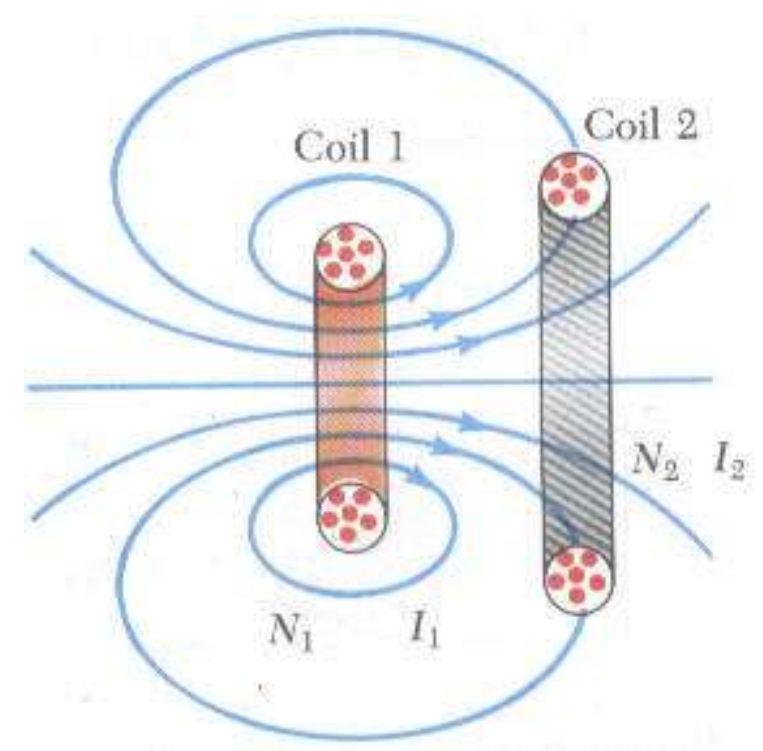

Fig. 2. Magnetic Induction Method

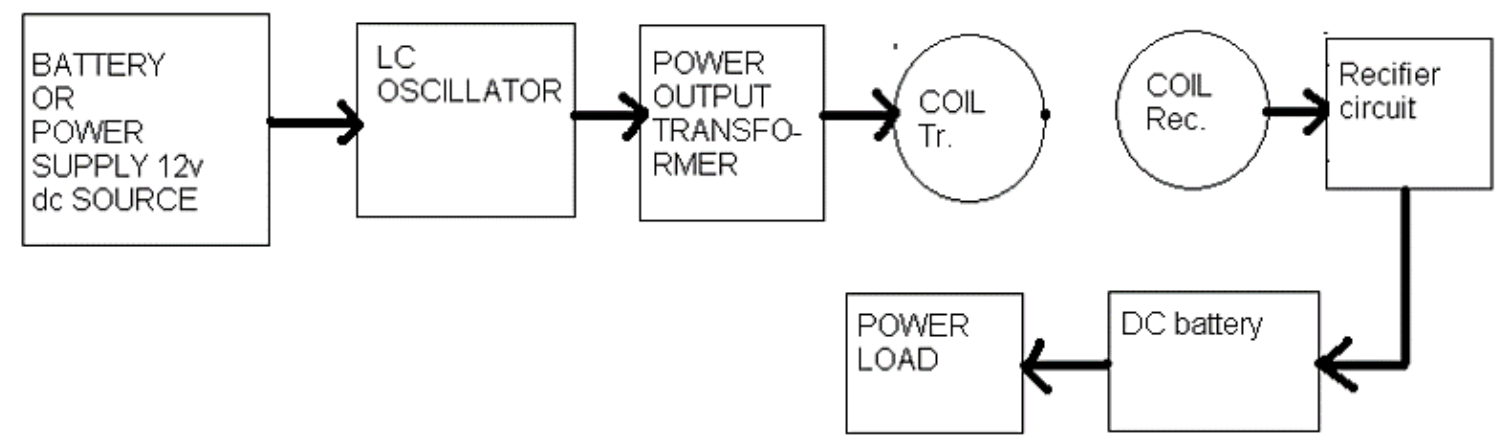

Fig. 3. Block Diagram of Magnetic Induction Method

\subsection{Electromagnetic Radiations Method}

This method is a radiative type. This method is used for wireless large distances transmission of information. Unfortunately, it is not usually used because of dissipating transmitted power in all directions which resulting in insufficient amount of power reaches at the receiver. 


\subsection{Optical Techniques Method}

This method uses laser to transmit power. So, it is a radiative type. The power is transferred in light form, then it is converted to electrical form at the receiver. This method uses directional electromagnetic waves. Thus, the power can be transmitted over large distances [6]. As a result of needed suitable line of sight, this method is unsuitable for wireless power transmission in case of mobile receiver. For rebuts operation, the transmitted media should be so clear, it means no object should be placed in between the transmitter and the receiver that will resist and may cause weakness or failure in transmission. To overcome this, the Complicated tracking techniques is used especially in mobility condition, but the cost of the power system is increased to a considerable level.

\subsection{Microwaves Method}

This method uses frequencies in microwave range. The power is transmitted over large distances using radiative antennas [7]. Thus, it is radiative type, this method is more efficient than others in wireless power transmission over long distances. However, this method is complicated, unsafe, and environmentally unfriendly due to microwave frequencies at higher power levels that can potentially harm people. Thus, the care instructions must be taken into account when using this method in higher power levels. This method is used to transmit power in the range of tens of kilowatts [8]. In 1964, a microwave powered helicopter model was presented by Brown [9]. In 1997, Reunion Island utilized this method for wireless power transmission [10].

There are two types of microwave systems, microwave tube and semiconductor amplifier. Figure 4 describes some examples of these types depending on the relation between the producer average power and the frequency bands [11]. These have electric characteristics contrary to each other. The microwave tube produce a high power microwave in a range over a kilowatt. The microwave tube system has numerous applications in life. One useful and helpful example of microwave tube which is used in life is the cooker-type magnetron that is called the microwave oven. It can produce and amplify high power microwave in the range over kilowatts and voltages in range over kilo volt. Magnetron has a high economical merit. Also, magnetron is used in radar systems.

Another type of microwave system is the semiconductor amplifier that produces a low power microwave range below hundred watts with a low voltage range below fifteen volt. According to generation or amplification efficiency, the microwave tube has higher efficiency than semiconductors. The microwave tube efficiency reach more than $70 \%$. In contrast, the semiconductors efficiency is below that $50 \%$. 


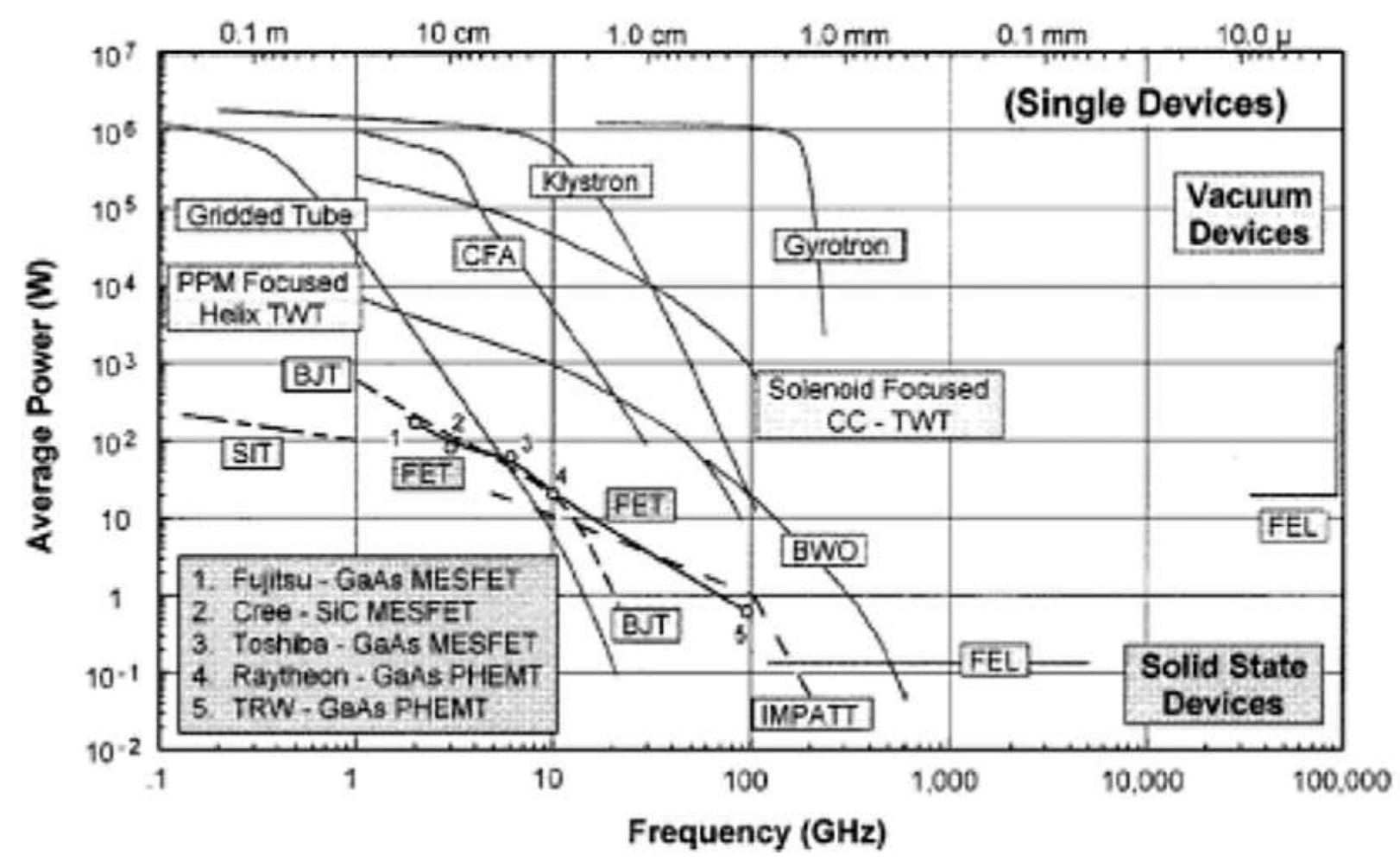

Fig. 4. Average Power Production versus Frequency for Various Electronic Devices and Semiconductors [11]

\subsection{Magnetron}

Magnetron is a high powered vacuum tube. It is a crossed field tube of electrical and magnetic field forces that are emitted from the cathode to the anode. The magnetron is auto oscillatory device as the anode has a resonant frequency. The magnetron is invented by A. W. Hull in 1921. The efficient magnetron's applications used to be the focus of the world. Magnetron technologies were advanced during the Second World War, especially in the Japanese Army. The magnetrons were mainly developed and manufactured for the microwave ovens. As a result, the magnetron of $500-1,000$ watts is widely used in microwave ovens in $2.45 \mathrm{GHz}$. It has global capacity of 45.5 giga watts per year for all magnetrons installed in microwave ovens. The magnetron is a microwave power transmitter proper device because of its high efficiency and low cost. But, it has demerits due to its unstable frequency and uncontrollable phase. But nowadays, the Kyoto University's system develops the magnetron to have a controlled beam in direction with phased arrays operated in 2.45 $\mathrm{GHz}$ and $5.8 \mathrm{GHz}[12]$.

\subsection{Traveling Wave Tube Amplifier (TWTA)}

Traveling Wave Tube (TWT) was created by R. Kompfner in the Second World War and was theoretically described by J. R. Pierce and L. M. Field in 1945. The TWT is a linear beam tube with snail structure. The snail slow wave structure slows the waves down closest the velocity of the electron beam. In the TWT, the interaction between the RF waves and the electron beam is continuous along the length of the SWS. The TWT can be used as amplifier. When using long tube, the gain will be high 
as it is direct proportional. The frequency band of the TWTA is very wide, as it ranges from $1 \mathrm{GHz}$ to $60 \mathrm{GHz}$. The TWT output power is a few hundred watts. There are numerous applications that use the TWTA like satellites, television broadcasting, and communication satellites. The TWTA has a proven track record in space. Before 1980s, the efficiency of the TWTA didn't exceed $30 \%$, thus it is unsuitable for power transmission. However, in recent years, TWTA uses a technique called velocity tapering energy recovery [13]. In this technique, the net transformation rate has increased to around $70 \%$ [14]. On one hand, the price of TWT has decreased due to development time, on the other hand the effort could be reduced as a result of the standardization of the product. Also, the parts cost could be reduced as a result of increasing demand parts. In addition, manufacturing cost could be reduced by manufacturing larger number of TWTAs in a time frame certain and by modern automation in the manufacturing process. Finally, the test time and effort has been reduced due to the higher credibility of the product. The TWT development direction becomes due to microwave power module and phased array for TWT. The semiconductor amplifiers, and the power supply technology make the microwave power module in a good candidate for space application because it has a high transformation efficiency, low weigh, and small size.

\subsection{Klystron}

The Varian brothers in the late 1930s invented klystron. The klystron is a linear beam cavities tube. Electrons are emitted from the cathode and the electron beam passes through the cavities. When generate wave trough cavity, the electron beam is modulated and the wave is amplified. The klystron consider as a high power amplifier from tens of kilo-watts to range of mega-watts. The klystron has high efficiency more than $70 \%$. It needs a heavy power supply and also a heavy magnet. The klystrons are used to broadcast applications in range of 400 to $850 \mathrm{MHz}$. The klystron was used in microwave power transmission in 1975 at the Venus Site of JPL Goldstone Facility. One klystron transmits microwave of 450 kilo-watts and $2.388 \mathrm{GHz}$. The klystron is suitable for large power transmission system such as SPS. The SPS was designed by NASA/DOE in 1980 with phased array of the klystrons. However, there has not been klystron phased array system yet [15].

\subsection{Electrodynamics Induction Method}

This method is a non-radiative, however, it is environmentally friendly. The principle of this method is described by two resonance objects that can exchange power when they possess the same frequency [16]. In medium transmitting range, the higher efficiency can be achieved. This method is a common widely method used for wireless power transmission because it is not needed to alignment transmitter and receiver. Thus, this method has a higher placement freedom. In 2007, researchers from Massachusetts Institute of Technology (MIT) utilized this method and powered a $60 \mathrm{~W}$ light-bulb wirelessly at a distance of 7 feet with an overall efficiency of $40 \%$ [17]. In 2008, Intel used the same method and powered a $60 \mathrm{~W}$ light-bulb wirelessly at a shorter distance with an overall efficiency of $75 \%$ [18]. In 2008, the same method was used by Lucas Jorgensen and Adam Culberson belonging to Cornell University and a successful experiment of wireless power transmission at a shorter distance was performed [19]. In 2011, Mandip Jung Sibakoti and Joey Hambleton belonging to 
Cornell University performed the same experiment and powered a $40 \mathrm{~W}$ light-bulb wirelessly at a shorter distance [20].

In the next table Different Wireless Power Technologies are presented. This table discusses distance range, directivity, frequency band, and form of antenna that are used in each technique method.

Table 1. Wireless power transmission methods characteristics

\begin{tabular}{|l|l|l|l|l|}
\hline Technology method & Range & Directivity & $\begin{array}{l}\text { Frequency } \\
\text { band }\end{array}$ & Antenna devices \\
\hline Inductive coupling & Short & Low & $\mathrm{Hz}-\mathrm{MHz}$ & Wire coils \\
\hline $\begin{array}{l}\text { Resonant inductive } \\
\text { coupling }\end{array}$ & Medium & Low & $\mathrm{MHz}-\mathrm{GHz}$ & $\begin{array}{l}\text { Tuned } \\
\text { coils, lumped } \\
\text { element } \\
\text { resonators }\end{array}$ \\
\hline Capacitive coupling & Short & Low & $\mathrm{KHz}-\mathrm{MHz}$ & Electrodes \\
\hline Magneto dynamics & Short & N.A & $\mathrm{Hz}$ & $\begin{array}{l}\text { Rotating } \\
\text { magnets }\end{array}$ \\
\hline Microwave & Long & High & $\mathrm{GHz}$ & $\begin{array}{l}\text { Parabolic } \\
\text { dishes, phased } \\
\text { arrays, } \\
\text { rectennas }\end{array}$ \\
\hline Light wave & Long & High & $\geq \mathrm{THz}$ & $\begin{array}{l}\text { Lasers, } \\
\text { photocells, } \\
\text { lenses, } \\
\text { telescopes }\end{array}$ \\
\hline
\end{tabular}

\section{Conclusion}

Nowadays the world is a contemporary technology era that is called industry 4.0. The demands of energy is increasing and the source of power should be found and created. Thus, the needs of power become indispensable. Tough and wireless power transmission take a wedge place of this technology. That is due to numerous applications that depends on electricity, whatever high power or low power. The wireless power called WiTricity as it is wireless electricity. The wireless power technique types are classified into radiative and non-radiative. Each one of these classifications has a sub- type. The radiative section contains electromagnetic, microwave and laser. This type concern a high power transmission. The other type is non-radiative that concern the low power. This type is divided into resonance and inductance coupling. All of these techniques depend on magnetic field theory which was invented by Nikola Tesla in the 1890s.

\section{References}

[1] N. Tesla, "Apparatus for Transmission of Electrical Energy," U.S. Patent 649621 , May 15, 1900. 
[2] Syed A. Nasar, "Schaum's Outline of Theory and Problems of Electric Machines and Electro mechanics", New York, McGraw-Hill Companies, Inc., v1, n2, ISBN: 0-07-045994-0, 1998.

[3] Dave Baarman and Joshua Schwannecke, "Understanding Wireless Power", December 2009

[4] The Economist, "Wireless charging, Adapter dies”, November 2008

[5] Fernandez J. M. and Borras J. A., "Contactless battery charger with wireless control link", U. S. Patent: 6,184,651, February 2001.

[6] Sahai A., Graham, and David, "Optical wireless power transmission at long wavelengths", IEEEICSOS, 2011, IEEE International Conference on Space Optical Systems and Applications, ISBN: 978-1-4244-9686-0, June 02, 2011.

[7] Landis G. A., "Applications for Space Power by Laser Transmission”, SPIEOEOLC 1994, Conference on SPIE Optics, Electro-optics, and Laser, v2121, p252-55, January 1994.

[8] Duke, Mystica Augustine Michael. "Wireless Power Transmission." International Journal of Scientific \& Engineering Research 5.10 (2014): 125-129.

[9] Brown W. C., Mims J. R., and Heenan N. I., "An Experimental Microwave-Powered Helicopter", IEEEICR 1964, 965 IEEE International Convention Record, v13, n5, p225-35, 1964.

[10] Lan Sun Luk J. D., Celeste A., Romanacce, Chane Kuang Sang L., and Gatina J. C., "Point-to-Point Wireless Power Transportation in Reunion Island", IAC 1997, 48th International Astronautical Congress, October 1997.

[11] Takano, T., A. Sugawara, and N. Kamo, "Simplification Techniques of the Constitution of Microwave Transmission Antennas of SPS (in Japanese)", Tech. Rep. of IEICE, SPS2003-09(SPS2004-02), 2004, pp.51-58

[12] Shinohara, N., H. Matsumoto, and K. Hashimoto, "Phase-Controlled Magnetron Development for SPORTS : Space Power Radio Transmission System", The Radio Science Bulletin, No.310, Sep. 2004, pp.29-35

[13] Granatstein, V. L., P. K. Parker, and C. M. Armstrong, "Scanning the Technology: Vacuum Electronics at the Dawn of the Twenty-First Century," Proc. IEEE, vol. 87, 1999, pp. 702-716

[14] Heider, S., "The Commercial Space TWTA Market Review and Trends", Proc. of 1997 ESA Workshop, 1997, pp.63-68

[15] Sivan, L., "Microwave Tube Transmitters - Microwave Technology Series 9-“, Chapman \& Hall, 1994

[16] Karalis A., Joannopoulos J. D., and Soljacic M., "Efficient Wireless Non-Radiative Mid-range Energy Transfer", Annals of Physics, 323, 2008, p34-48, April 27, 2007.

[17] EetIndia.co.in, "MIT lights $60 \mathrm{~W}$ light-bulb by wireless power transmission”, 11 Jun 2007

[18] TG Daily, "Intel imagines wireless power for your laptop", August 2008

[19] Lucas Jorgensen and Adam Culberson, "Wireless Power Transmission Using Magnetic Resonance", 2008

[20] Mandip Jung Sibakoti and Joey Hambleton, "Wireless Power Transmission Using Magnetic Resonance", December 2011 